\title{
Empirical flash flood vulnerability functions for residential buildings
}

\author{
Chiara Arrighi $^{1}$ (D) $\cdot$ Bernardo Mazzanti ${ }^{2} \cdot$ Francesco Pistone $^{2} \cdot$ Fabio Castelli $^{1}$
}

Received: 6 February 2020 / Accepted: 4 April 2020 / Published online: 15 April 2020

(c) Springer Nature Switzerland AG 2020

\begin{abstract}
The estimation of flood losses is crucial for the quantitative estimation of risk and the cost-benefit analysis of risk mitigation and prevention measures. Flood losses are usually estimated by means of vulnerability functions, which are often developed in a synthetic way by experts, since loss datasets collected after events are sparse or lacking and mostly refer to slow riverine inundations. Simple univariable empirical vulnerability functions are recognized as a more valuable tool with respect to synthetic curves developed for different contexts. The aim of this work is to derive empirical vulnerability functions for a flash flood event which occurred in Livorno (Italy) in September 2017, based on the hydrologic-hydraulic reconstruction of the flood and observed losses to residential properties. The hydrologic processes are reproduced with a distributed hydrologic model, and the flood propagation is simulated with a full 2D model. Many open GIS data are used and combined with virtual on-site inspection in the study area to analyze building exposure. Different regression curves are tested to fit the data and obtain damage curves. The results show (i) a poor correlation between relative or absolute losses and flow velocity, (ii) a low correlation between relative losses and water depth, thus confirming the existing literature. More significant correlation is found between absolute losses and water depths. The curves here derived provide a first attempt to develop damage functions for flash flood in Italy, which could be applied in similar urban and morphologic contexts.
\end{abstract}

Keywords Flood risk · Flood vulnerability · Stage-damage function · Flash flood · Flood damage

\section{Introduction}

Overall economic losses caused by natural disasters are increasing worldwide. Hydrologic disasters (i.e., floods, rainstorms, etc.) are the most frequent events, causing significant damages and affecting large portions of the population. The IPCC and the scientific community suggest that frequency and magnitude of flood events are going to increase due to climate change [1]. Moreover, socioeconomic development is expected to increase exposure to those events [2].

Vulnerability is a key component of flood risk and is commonly defined as the potential of being harmed by the flood [3]. Vulnerability is often represented in terms of stage-damage functions, also called damage functions in the literature, which are associated with a flood parameter, commonly water depth, a relative amount of loss or an absolute monetary loss. Vulnerability functions are often developed based on expert judgment [4-6], and sometimes they are derived from observed losses [7-9]. Recently also some physical laboratory models have been developed to better investigate the key damage mechanisms [10, 11]. Vulnerability functions have been developed for transportation systems [12], agriculture [13] and buildings. Most of the literature focused on residential buildings damaged by riverine flooding [14], and there are few examples of empirical vulnerability analysis for flash flood or debris flows $[15,16]$. Laudan et al. [16] adopted a random forest approach to determine the importance of contributing variables, e.g., flood depth, flow direction,

Chiara Arrighi, chiara.arrighi@unifi.it | 1 Department of Civil and Environmental Engineering, Università degli studi di Firenze, Florence, Italy. ${ }^{2}$ Hydrology Department, Regione Toscana, Florence, Italy. 
year of construction, and correlated six qualitative damage grades to inundation depths. Fuchs et al. [15] focused on the relationship between debris flow intensity and relative vulnerability in a mountainous catchment. Thus, empirical flash flood vulnerability functions allowing for monetary damage estimation in urban areas, like the one presented in the study, are lacking.

Other inundation parameters are also used in the literature to better define vulnerability such as flow velocity, presence of contamination, flood duration, etc., and they are usually based on large dataset and learning algorithms $[7,8]$. However, several uncertainties affect simulated inundation parameters which might alter the estimated losses $[17,18]$.

Moreover, common building parameters used for the vulnerability assessment of residential buildings are surface area, number of floors, presence of cellar/basement. These are usually retrieved based on digital cartographic information or on-site inspection.

Frequently, the lack of data on losses induces experts to define synthetic stage-damage functions with poor validation. That is why there is a general agreement in the scientific community that damage data should be systematically collected and interpreted in order to better assess ex ante potential losses [19]. Transferability of vulnerability functions is also debated since building features and typologies change significantly from country to country (or regions) [20]. Recent studies concluded that even simple stage-damage curves based on local data are more accurate than literature models derived in different contexts [7].

In September 2017, the city of Livorno, in the Tyrrhenian coast of central Italy, was hit by an exceptional short precipitation event characterized by very high rainfall intensity $\left(>100 \mathrm{mmh}^{-1}\right)$ that persisted on a small portion of territory causing huge rainfall accumulations ( $>260 \mathrm{~mm}$ ) [21]. The consequences were not only economic damages to structures and infrastructures, but eight people lost their lives. After the event, loss data have been collected by the regional civil protection office in order to start claiming procedures.

The objective of this manuscript is to determine a vulnerability function for residential buildings based on observed losses and on the reconstructed inundation, which can be used in similar regional contexts. The flash flood event is reconstructed using the recorded precipitation as input data. A fully distributed hydrologic model and a 2D hydraulic model are adopted to transform the observed precipitation into a flood map, which is validated against observed inundation extent. The digital cartography is used to identify residential buildings, their characteristics and their monetary exposure. With respect to other studies in the literature which focus on slow riverine floods, this work focuses on a number of observed losses related to a flash flood and offers insights on damage mechanisms rarely observed and studied [16].

The study is structured into three components:

- First, a simulated flood depth map is obtained based on the hydrologic model fed with recorded event precipitation and the high-resolution hydraulic model which also accounts for the storage basins constructed in the catchment.

- Second, exposure data (surface area, building type, market value) have been analyzed at single-building scale in a GIS environment and observed losses have been georeferenced.

- Third, absolute and relative vulnerability curves have been drawn versus flood depth, velocity and flow magnitude to evaluate their role in flash flood. Several regression models have been tested also including uncertainty/errors in simulated water depth.

\section{Study area}

The study area is located on the coast of Tuscany (central Italy) in the municipality of Livorno (Fig. 1, panel b). The Rio Maggiore creek flowing from right to left with reference to Fig. 1 is analyzed. The creek crosses hilly, mildly steep terrain (about 300 m.a.s.l. in the upper catchment) and then reaches the coastal floodplain where the city of Livorno is located. The catchment area is $8 \mathrm{~km}^{2}$ and the stream length is $12 \mathrm{~km}$. In September 2017, the precipitation event hit many small catchments in the area with the major losses caused by the inundations of Rio Maggiore and Ardenza. The inundated area recorded by regional offices is about $1.15 \mathrm{~km}^{2}$, and the population affected is about 4000 . There were four fatalities in just one property in Rio Maggiore catchment and four fatalities in Ardenza catchment. Authorities collected 302 compensation forms filled by the affected citizens in the area (Fig. 2, panels a, c), which have been later georeferenced by the civil protection offices. Compensations refer to damages to structures (e.g., foundations, retaining walls, interior flooring, plastering, etc.).

The geographic data and the observed variables used or simulated in the study are summarized in Table 1. They are classified based on the workflow in hydrologic, hydraulic and exposure/vulnerability data, and they are all download-free except for the observed losses and inundated areas provided by regional offices. 


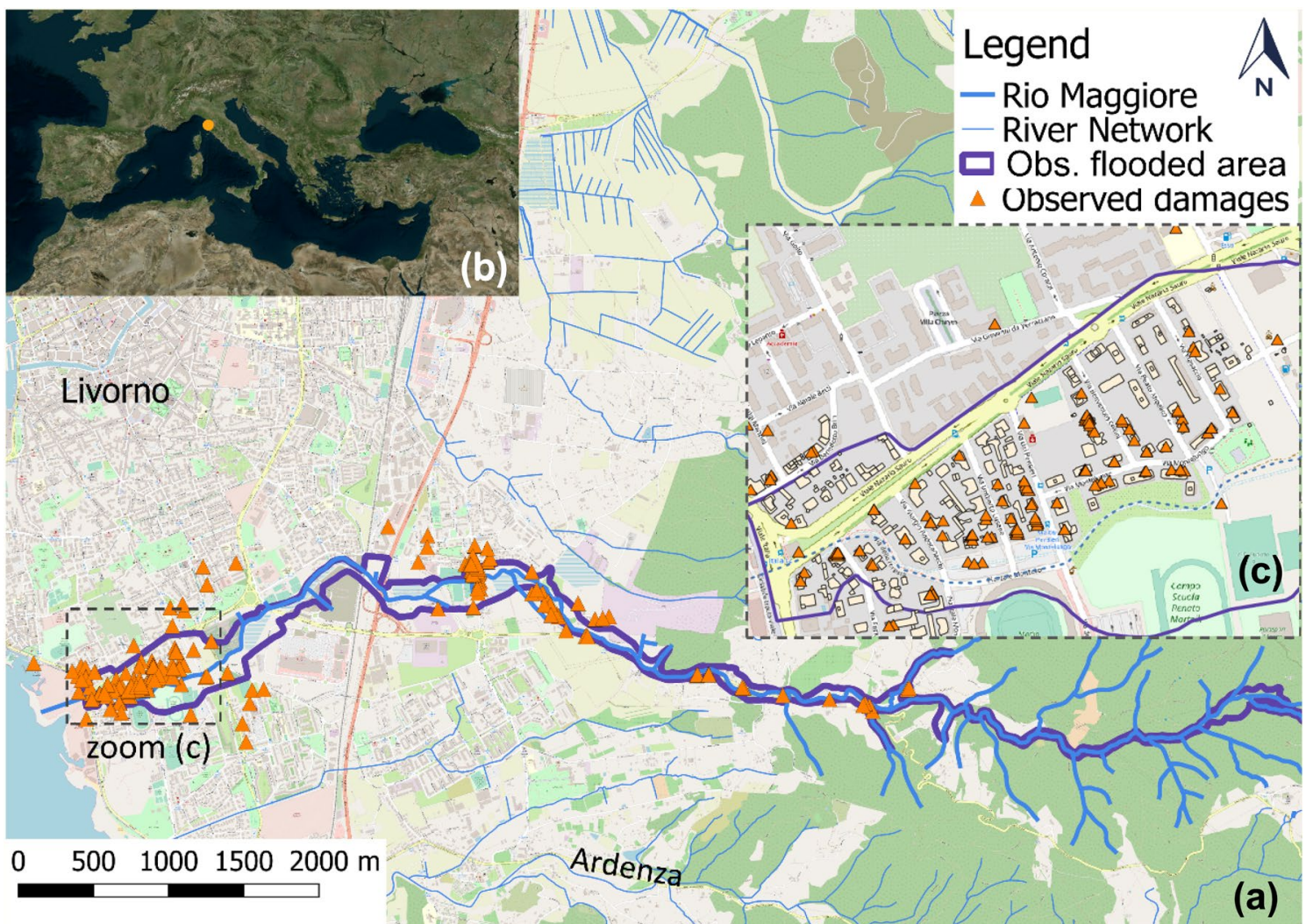

Fig. 1 Rio Maggiore area with location of observed damages and observed inundated area (a), position of Livorno in the Northern Mediterranean region (b), detail of observed damages (c)

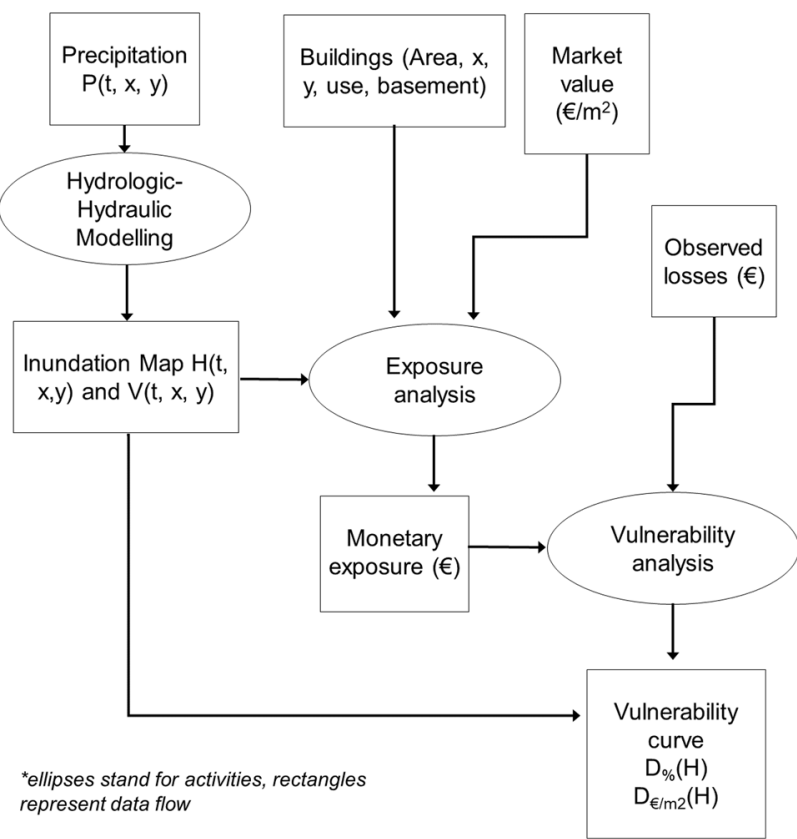

Fig. 2 Diagram of the methodology of the study

\section{Method}

This work combines several models and observations to extract vulnerability curves for residential buildings. The hydraulic variable of the vulnerability curve is the flood depth, which is obtained by simulating the transformation of precipitation into river discharge (hydrologic model) and the propagation of the discharge in the territory (hydraulic model). The degree of vulnerability is estimated in both relative and absolute terms; thus, the estimation of exposure is required. The method is summarized in Fig. 2 .

\subsection{Hydrologic and hydraulic model}

The precipitation data recorded during the flood event by the regional hydrologic service have been used as input of the hydrologic model [21]. The rainfall-runoff simulation has been carried out using MOBIDIC (MOdello di Bilancio Idrologico DIstribuito e Continuo), a fully distributed, raster-based hydrologic balance model [22-24]. MOBIDIC simulates the water balance in a series of reservoirs (gravitational storage $W_{g^{\prime}}$ capillary storage $W_{c^{\prime}}$ groundwater storage $H$, surface storage $W_{s}$ and the river system) and fluxes between them (precipitation $P$, 
Table 1 Data observed and simulated for the hazard, exposure and vulnerability analysis

\begin{tabular}{|c|c|c|c|c|c|}
\hline Analysis & Data & Observed & Simulated & $\begin{array}{l}\text { Exter- } \\
\text { nal } \\
\text { Source }\end{array}$ & Description and source \\
\hline \multirow[t]{4}{*}{ Hydrologic model } & DTM $10 \times 10 \mathrm{~m}$ & & & $x$ & Digital Terrain Model (depicted), Regione Toscana \\
\hline & Precipitation (mm) & $x$ & & & $\begin{array}{l}\text { Event precipitation available from pluviometric } \\
\text { station, Regione Toscana hydrologic service }\end{array}$ \\
\hline & Pedology & & & $x$ & 1:25,000 soil cartography, Regione Toscana \\
\hline & River discharge $\left(\mathrm{m}^{3} / \mathrm{s}\right)$ & & $x$ & & Distributed hydrologic model MOBIDIC \\
\hline \multirow[t]{6}{*}{ Hydraulic model } & Inundated area & $x$ & & & Post-event survey, Regione Toscana \\
\hline & DTM $1 \times 1 \mathrm{~m}$ & & & $\mathrm{x}$ & $\begin{array}{l}\text { LiDAR-derived Digital Terrain Model, Regione } \\
\text { Toscana }\end{array}$ \\
\hline & Roughness $\left(\mathrm{s} / \mathrm{m}^{0.33}\right)$ & & & $x$ & $\begin{array}{l}\text { Assumed from land use cartography, CORINE } \\
\text { Land Cover }\end{array}$ \\
\hline & Hydraulic works geometry & & & $\mathrm{x}$ & $\begin{array}{l}\text { Projects of hydraulic works, Municipality of } \\
\text { Livorno }\end{array}$ \\
\hline & Maximum water depth (m) & & $\mathrm{x}$ & & Full 2D hydrodynamic model \\
\hline & Maximum flow velocity $(\mathrm{m} / \mathrm{s})$ & & $\mathrm{x}$ & & Full 2D hydrodynamic model \\
\hline \multirow{6}{*}{$\begin{array}{l}\text { Exposure and } \\
\text { vulnerability } \\
\text { model }\end{array}$} & Monetary damage to properties $(€)$ & $\mathrm{x}$ & & & Official claims, Civil Protection Regione Toscana \\
\hline & Building use (-) & $x$ & & & $\begin{array}{l}\text { Classified based on virtual Google Street View } \\
\text { inspection }\end{array}$ \\
\hline & Number of floors (-) & & & $x$ & $\begin{array}{l}\text { Classified based on virtual Google Street View } \\
\text { inspection }\end{array}$ \\
\hline & Presence of cellar (-) & $\mathrm{x}$ & & & $\begin{array}{l}\text { Classified based on virtual Google Street View } \\
\text { inspection }\end{array}$ \\
\hline & Building value $\left(€ / \mathrm{m}^{2}\right)$ & & & $x$ & Market prices, Agenzia del Territorio \\
\hline & Building area $\left(\mathrm{m}^{2}\right)$ & & & $x$ & 1:2000 cartography, Regione Toscana \\
\hline
\end{tabular}

infiltration $I_{\text {nf }}$ adsorption $A_{\mathrm{d}}$, percolation $P_{c^{\prime}}$ surface runoff $R$, interflow $Q_{d}$, groundwater discharge $Q_{g}$ ) [22-24]. Once the surface runoff $\left(Q_{\mathrm{d}}\right.$ plus $\left.R\right)$ and baseflow are calculated, three different methods can be used for river routing, i.e., the lag method, the linear reservoir method and the Muskingum-Cunge method. For further details on the equations and assumptions, consult the references [22, 24]. Besides rainfall data, the most relevant input data to the model are the river network, the digital terrain model ( $10 \mathrm{~m}$ resolution) and the regional soil map (scale 1:250,000) (see Table 1). The initial soil moisture state has been assumed equal to $80 \%$ of saturation to be compared with previous analyses.

The hydraulic model adopted to simulate the propagation of the event in the floodplain area is HEC-RAS v5.0.7. This version allows to compute with 2D diffusive approximation or full momentum equation the motion of the fluid over a structured/unstructured computational mesh with steady or unsteady flows. The capabilities of the software are fully described in the reference manual [25].

For reproducing the Livorno flood, both the river and the floodplain have been resolved with the 2D full momentum equations. The mesh has been defined over a $3 \mathrm{~km}^{2}$ area with maximum cell size of $5 \mathrm{~m}$ and minimum cell size of $0.5 \mathrm{~m}$ inside the river bed using GIS breaklines constraints. The terrain elevation associated with the mesh cells is obtained by a LiDAR-derived, 1-m-resolution DTM where buildings have been represented as waterproof block by manually assigning a high elevation to their footprint.

The inflow hydrographs of the main channel and of the tributaries obtained in the hydrologic simulation have been assigned as upstream boundary conditions. The simulated hydrograph of Rio Maggiore has been validated against the recorded hydrograph. The downstream boundary condition is a rating curve at the entrance of a 700-m-long culvert obtained by previous 1D hydraulic models carried out for the design of the retention basins. At the downstream boundary, a normal depth condition has been imposed (Fig. 3). Four storage areas with fixed elevation weirs have been also connected to the river to simulate their retention effect.

The manning roughness has been assigned based on the second level of land use (CORINE Land Cover). For urbanized areas, the Manning's value has been set to 0.01 (asphalt); for pastures and agricultural lands, set to 0.04 ; for woods, set to 0.06 ; and for the channel, set to 0.035 [26]. These values have been calibrated in their significant range, to obtain the best representation of the inundation extent. 


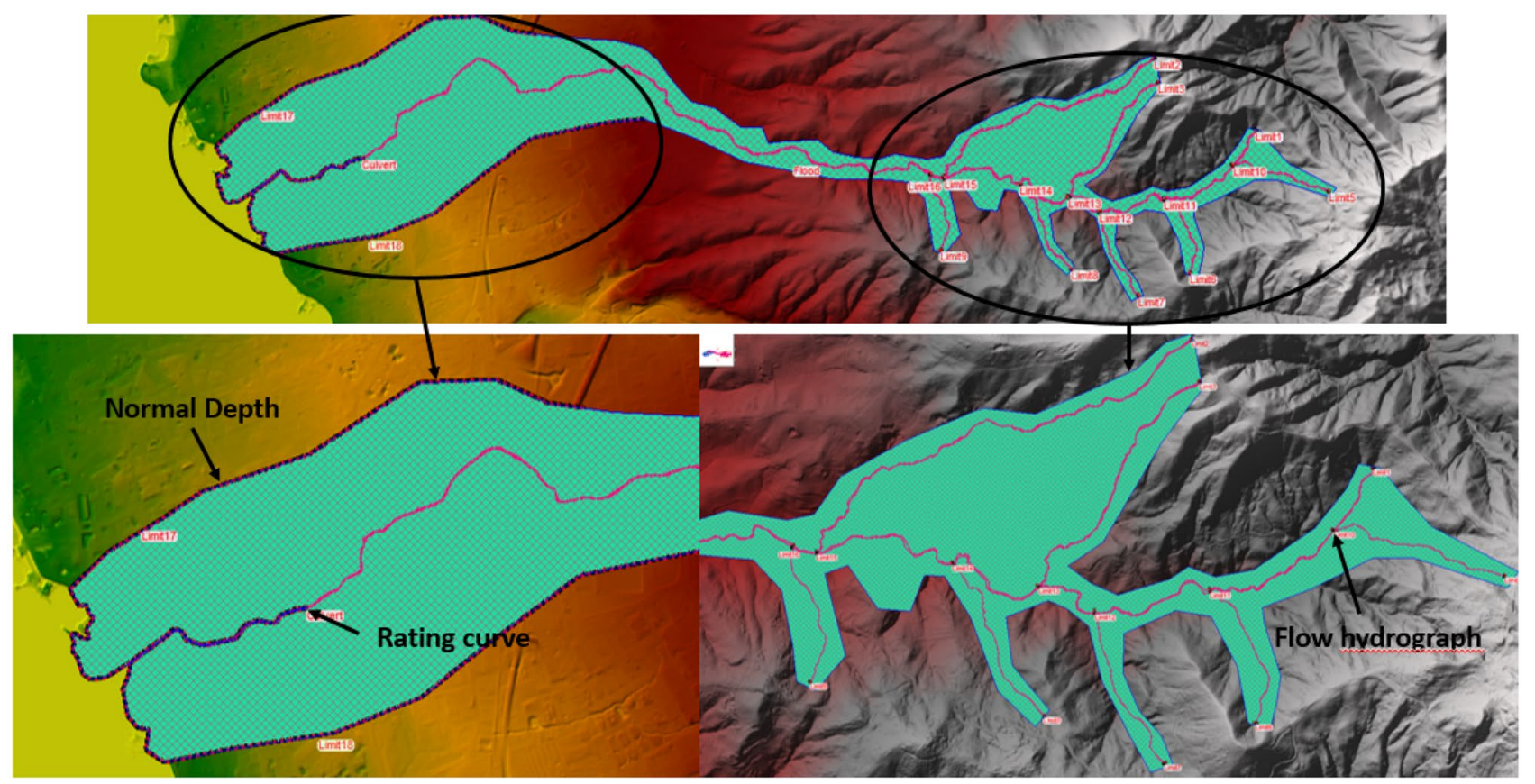

Fig. 3 Hydraulic model boundary conditions set in HEC-RAS

In the computational settings of the simulation, an adjustable time step based on a maximum Courant number of 0.6 has been selected to ensure the stability.

\subsection{Exposure model and vulnerability estimation}

A first metric of exposure is the surface area of the buildings affected by the flood $A\left(\mathrm{~m}^{2}\right)$. This is retrieved by the shapefile of the regional 1:2000 cartography. Other necessary information is the number of floors and the presence of an underground cellar or basement. The number of floors $f$ and the presence of cellar are not available as attributes. Thus, a virtual on-site inspection has been carried out using Google Street View and the presence of an underground floor has been added as a building feature attribute in QGIS. Similarly, also the building use has been classified and assigned as a new shapefile attribute. This is especially important for dual-use buildings, i.e., those with commercial activity in the ground floor and residences above, which are not classified in the official cartography.

The monetary exposure of the building $E_{\mathrm{b}}$ is obtained by multiplying the surface area of the ground floor of residential buildings $A_{\mathrm{b}}$ for the official market values $V_{\mathrm{m}}$ [27] at the time of the inundation (Eq. 1). For buildings with underground story, the value of the basement has been added. When the basement is used as a garage or cellar, the market value has been considered one-fourth of the residential value.
$E_{\mathrm{b}}=\sum_{i=1}^{f} V_{\mathrm{m}} \cdot A_{\mathrm{b}}$

where $f$ is the number of affected floors (mainly ground floor and basement where present) and $V_{m}$ is one-fourth of its value for underground floors.

The observed losses have been aggregated at the single building $L_{b}$; that is, all the ith damages of the properties (i.e., different owners from 1 to $n$ ) that occurred in a building have been summed up and associated as an attribute of the building feature.

$L_{\mathrm{b}}=\sum_{i=1}^{n} L_{i}$

This operation is necessary because the prevailing property types are small condominiums and the area of the single damaged property was not available. The relative loss $D_{\%}$ is obtained by dividing the observed aggregated damage $L_{b}$ by the market value of the affected floors.

$D_{\%}=\frac{L_{\mathrm{b}}}{E_{\mathrm{b}}} \cdot 100$

The absolute loss per unit surface $D_{\epsilon}$ is obtained by dividing the observed aggregated damage $L_{\mathrm{b}}$ by the surface of the building $A_{b}$.

The results of the hydraulic models are also aggregated to each affected building. Based on raster zonal statistics, 
each affected building is assigned a mean, maximum, minimum and standard deviation of water depth and velocity extracted from the raster maps of the event temporal maxima.

The buildings have now attributes associated with the hydraulic parameters and loss parameters. The first vulnerability curve is obtained by plotting mean water depth and relative loss $D_{\%}$. The second vulnerability curve is obtained by plotting mean water depth and absolute loss per unit area $D_{\epsilon}$.

\section{Results and discussion}

\subsection{Inundation map}

The very intense rainfall event simulated in MOBIDIC created a sharp hydrograph in the Rio Maggiore with a duration of $6 \mathrm{~h}$ and a peak of $141 \mathrm{~m}^{3} / \mathrm{s}$ which was estimated to be 1.3-1.4 times larger than the 200-yearreturn-period design hydrograph in its urban reach [21]. The result of the $2 \mathrm{D}$ hydraulic simulation in terms of maximum water depth is shown in Fig. 4. In the urban downstream area, flood depths are mostly equal to or lower than $1 \mathrm{~m}$. Higher flood depths of about $3 \mathrm{~m}$ are observed in the four designed storage areas. The simulated depths are coherent with the recorded inundated area except in a couple of zones. Upstream (right side of Fig. 4), the inundated area is underestimated because during the event, the low-span bridges in that area were obstructed by wood debris and the numerical model does not account for this behavior. In the suburban area (center of Fig. 4), the model overestimated the flood depths. This has been interpreted with the difficulties of the DTM altimetry in capturing the complex systems of infrastructures: the highway, (pink line in the north-south direction) and the railway (almost parallel to the highway) with their embankments and crossings. However, in that area, there are not buildings (and consequently claims); thus, it does not affect the empirical vulnerability curve. A slight overestimation of inundated area with respect to the observation can be seen downstream (lower left of Fig. 4). However, according to the claims (compare Fig. 1, panel c), also an area outside the official zonation has been affected.

Georeferenced images taken in the aftermath of the flash flood in the downstream urban area have been used to validate flood depths with differences in the order of 0.10-0.20 m, compatible with the morphological uncertainties in dense urban areas.

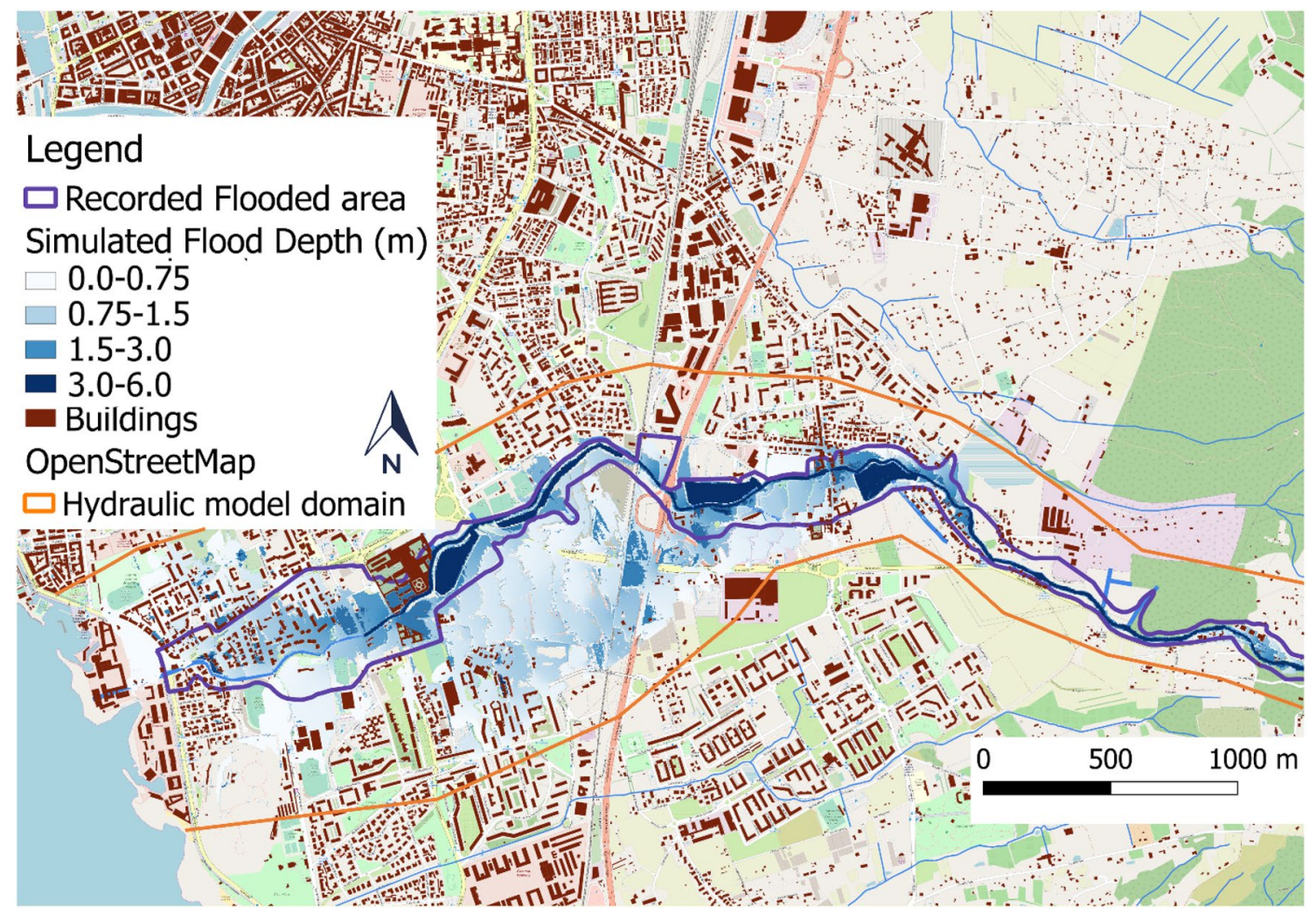

Fig. 4 Simulated flood depth map. The blue and orange lines show the inundation area recorded in the aftermath of the event and the simulation domain, respectively 
Figure 5 shows the simulated flood magnitude, i.e., the product of water depth and velocity. The magnitude is equal to or larger than one for most of the inundated area since flow velocities were of the order of $4-5 \mathrm{~m} / \mathrm{s}$ in the channel and 1-2 m/s in the flood plain, especially in the inundated area near the culverted reach. This poses people's safety under serious threat since pedestrians and vehicles can be easily swept away in this condition [28, 29]. However, the event took place at late night and fortunately there were not people walking or driving in the area.

\subsection{Exposure and vulnerability analysis}

The classification of exposed buildings carried out by a virtual inspection with Google Street View allowed to classify one thousand buildings in the observed flooded area; 719 items are residential buildings, 20 are dual-use buildings with commercial activities on the ground floor and 125 are commercial buildings. Figure 6 shows the results of the exposure analysis for the downstream part of Rio Maggiore catchment where it flows in the culvert. The building use was used to calculate monetary exposure of the buildings based on market values (Eq. 1). Only residential buildings were considered for the vulnerability curves.
With the same approach, the presence of an underground floor was detected. Figure 7 shows for the same area the information related to underground floors. Twenty-one buildings have an underground floor used as a residence, and seven have an underground garage. The range of residential market values in the area is $1600-1950 € / \mathrm{m}^{2}$ and $1950-2250 € / \mathrm{m}^{2}$ for the inner and coastal areas (Fig. 6), respectively.

The 302 compensation claims for residential properties were selected. The claims aggregated to single building became 93 observation points to build the empirical vulnerability curves. The analysis has not been carried out on buildings without residential use (i.e., offices, shops, warehouses) since only 59 claims were available in the observed inundated area.

Water depth was assigned to each building based on the raster statistics of a $3 \mathrm{~m}$ buffer around the building. Figure 8 shows the scatter plot of relative damage vs the water depth. The standard deviation of water depth is represented with error bars. This information shows the uncertainty introduced by calculating a single average value of water depth per building. For large structures in fact, there might be a significant difference in the water depth at different sides of the construction.

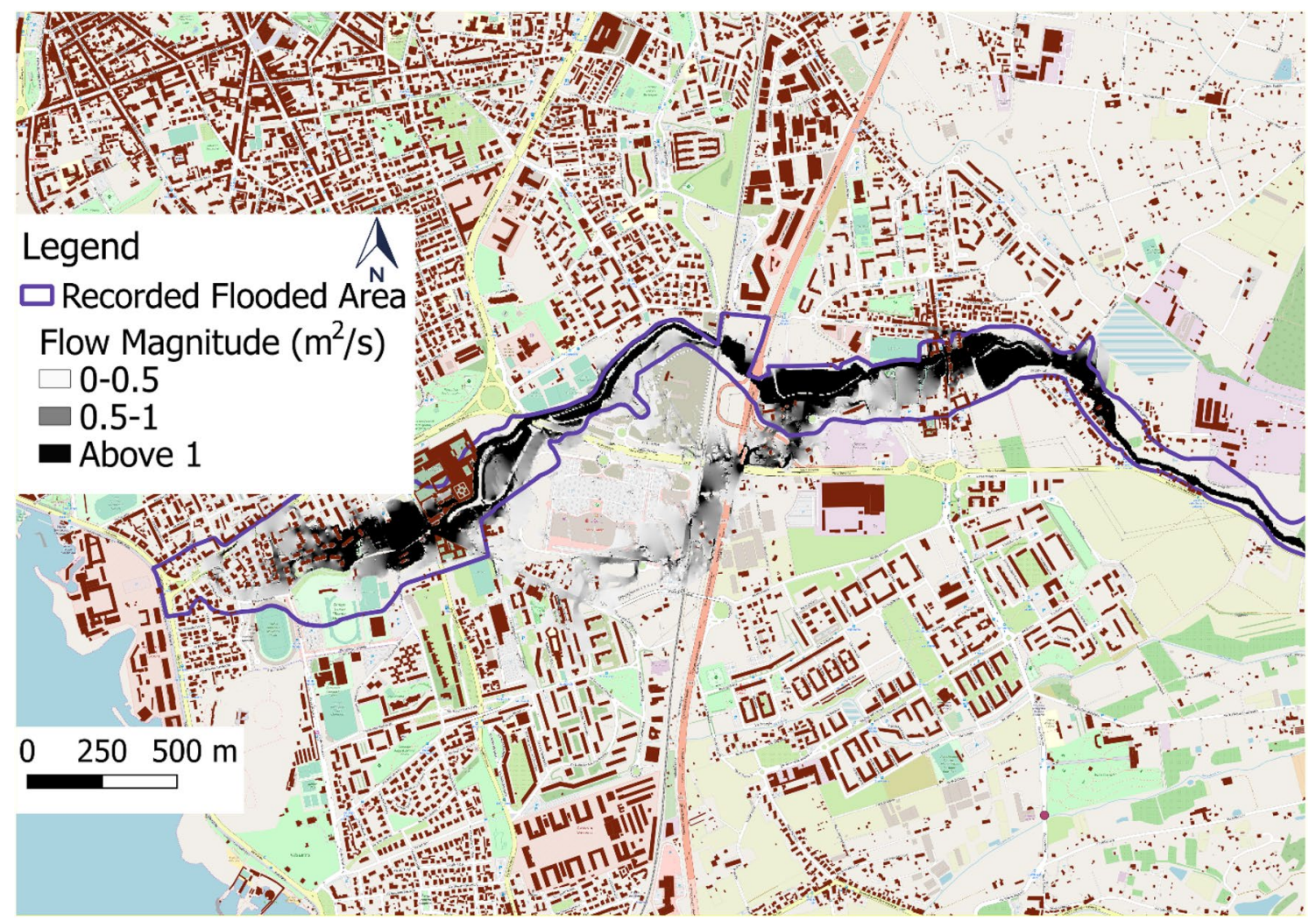

Fig. 5 Simulated flow magnitude (water depth multiplied by velocity) 


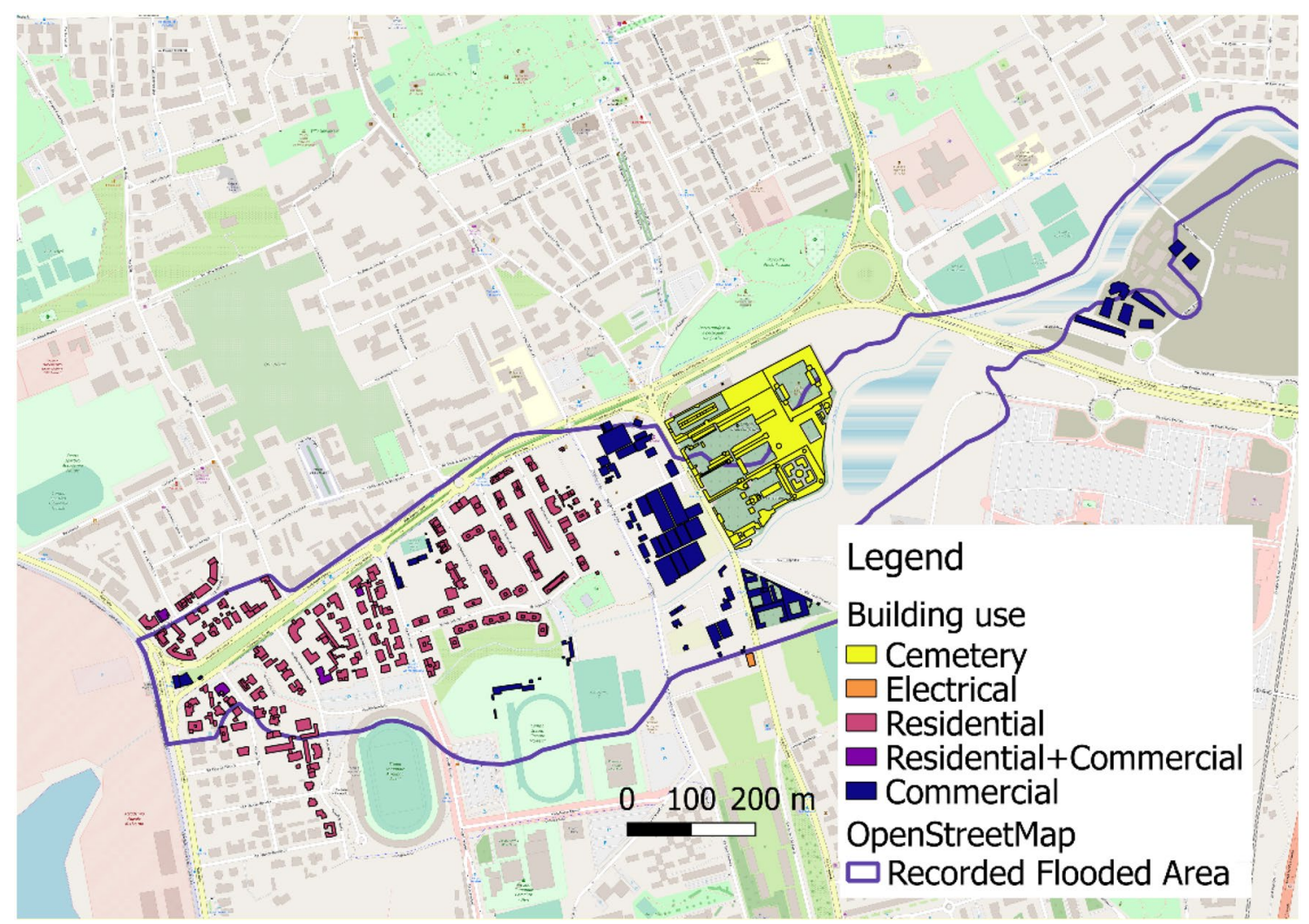

Fig. 6 Classification of the building use in the most downstream section of Rio Maggiore basin

Error bars on the vertical axes show the range of relative loss due to the variability of market values used for exposure assessment. The points are very sparse, and no clear correlation between water depth and damage is observed as in other cases in the literature [7].

Three types of least-square regression curves have been tested: linear, second-order polynomial and power. Table 2 shows the equations of the three regression curves, the determination coefficient and the rootmean-square error (RMSE). The performances of the three curves are comparable in terms of RMSE and $R^{2}$; the second-order polynomial has the highest $R^{2}$. The square-root regression damage model developed by Carisi et al. [7] for the Secchia River flood has also been tested since it represents the geographically closest example of empirical vulnerability curve. Nevertheless, buildings and inundation characteristics are different.

The scatter plot of absolute damage per unit surface vs the water depth has been derived and not reported here for brevity. Also in this case, the regression curves are not able to fully explain the variability of the observed losses, although higher determination coefficients are obtained (Table 3). No significant correlation has been found with a power law, which is omitted from Table 3.
The correlation of relative and absolute losses with flow velocity and magnitude is even lower than with water depths $\left(R^{2}<0.1\right)$; thus, these curves are not shown for the sake of brevity.

A more simplified empirical damage model is obtained by binning water depth values into classes and calculating the median damage in each bin [7]. The median damage is associated to the mean water depth of the bin. The process is limited to $1.5 \mathrm{~m}$ since only a couple of data exceed this water depth (Table 4). The obtained determination coefficients and RMSE are comparable to the linear law of Table $2\left(R^{2}=0.19\right.$, RMSE $\left.=24.7 \%\right)$.

Average damages aggregated to single affected residential building in the study area are of the order of 40,500 $€$ for simulated water depths between 0.15 and $1.5 \mathrm{~m}$. This corresponds to an average absolute damage of $270 € / \mathrm{m}^{2}$. Single-owner claims are of the order of $18,000 €$ on average and are clustered in two groups. The $30 \%$ of the claims are of the order of $1000 €$ and might indicate moderate losses to garages or condominium common parts.

Relative damage is about $12 \%$ on average with a standard variation of $22 \%$. The dispersion of relative and absolute loss data with a consequent lower correlation with flood parameters can be due to the uncertainties of the hydrologic-hydraulic model and to the 


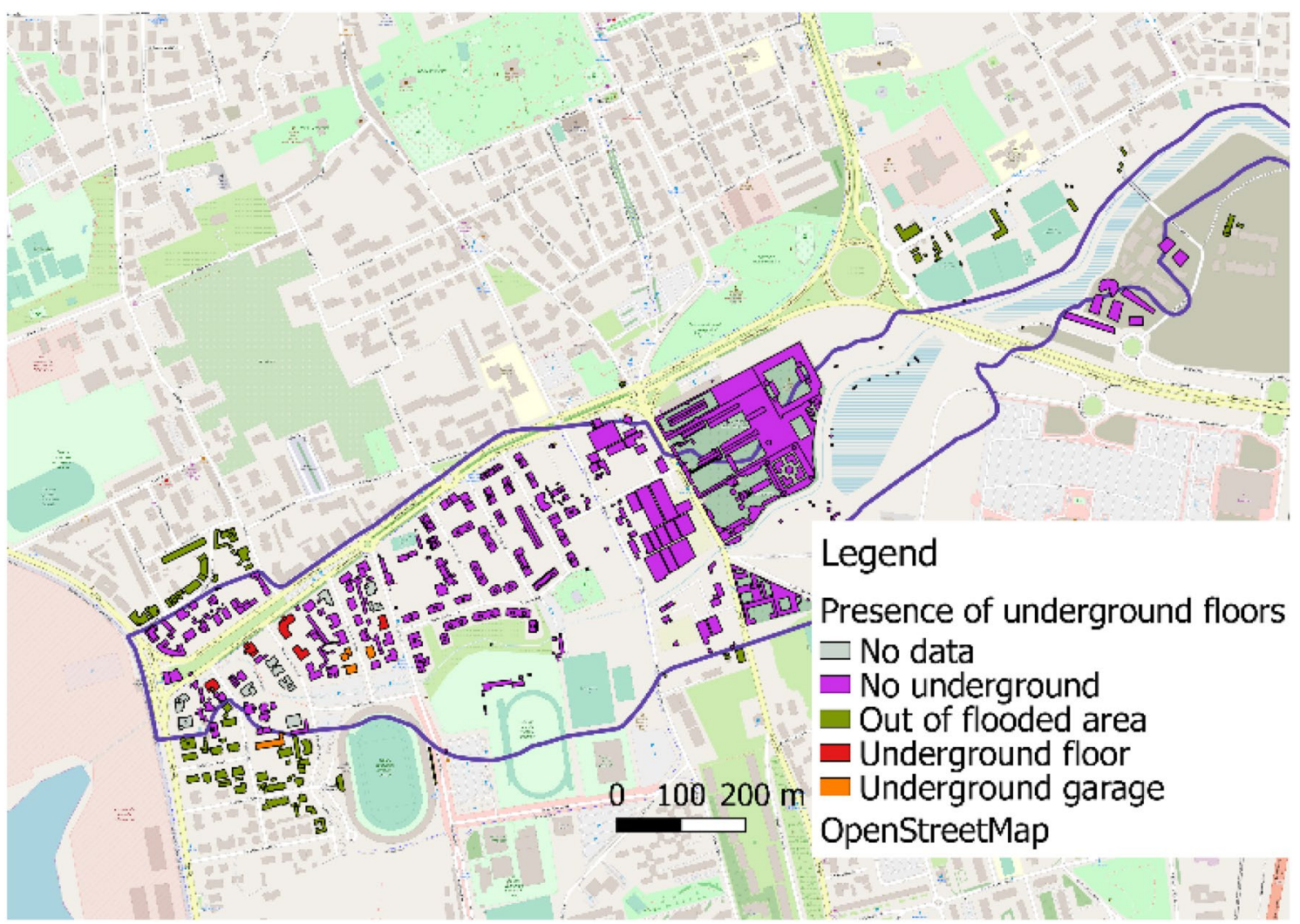

Fig. 7 Classification of the buildings based on the presence of underground floors in the most downstream section of Rio Maggiore basin

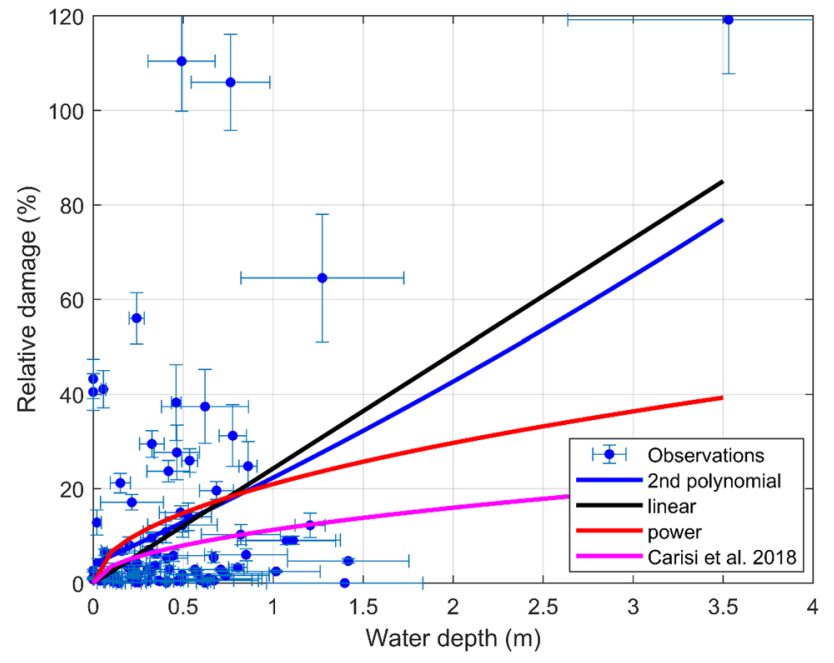

Fig. 8 Empirical relative stage-damage curve

errors introduced in aggregation a single mean water depth value to each building. However, other case studies in the literature in different urban and flood contexts show that the correlation among observed losses and flood depth is very low also when the inundation depth is measured [30]. Other reasons for poor correlation are
Table 2 Regression curves, determination coefficient and RMSE for the relative damage curve

\begin{tabular}{llll}
\hline Regression curve & Equation & $R^{2}$ & RMSE (\%) \\
\hline Second-order polynomial & $D_{\%}=4.02 \cdot \mathrm{H}^{2}+17.33 \cdot \mathrm{H}$ & 0.22 & 20.22 \\
Linear & $D_{\%}=24.3 \cdot \mathrm{H}$ & 0.19 & 20.3 \\
Power & $D_{\%}=21 \cdot \mathrm{H}^{0.5}$ & 0.11 & 21.5 \\
Carisi et al. [7] & $D_{\%}=11.3 \cdot \mathrm{H}^{0.5}$ & 0.01 & 25.6 \\
\hline
\end{tabular}

Table 3 Regression curves, determination coefficient and RMSE for the absolute damage curve

\begin{tabular}{llll}
\hline Regression curve & Equation & $R^{2}$ & $\operatorname{RMSE}\left(€ / \mathrm{m}^{2}\right)$ \\
\hline $\begin{array}{l}\text { Second-order polyno- } \\
\text { mial }\end{array}$ & $D_{€}=523.8 \cdot \mathrm{H}^{2}+0.64 \cdot \mathrm{H}$ & 0.37 & 478.5 \\
Linear & $D_{\epsilon}=711.2 \cdot \mathrm{H}$ & 0.49 & 431.0 \\
\hline
\end{tabular}

a consequence of several other local factors such as (i) the adoption of individual mitigation actions (also involuntary), (ii) the low trust in the reimbursement by the institution and preferences for the black market, (iii) partial request of damages (e.g., only boiler instead of the whole room where the boiler is located), (iv) different 
Table 4 Empirical damage curve obtained by the binning procedure

\begin{tabular}{ll}
\hline Water depth $(\mathrm{m})$ & $\begin{array}{l}\text { Relative } \\
\text { damage } \\
(\%)\end{array}$ \\
\hline 0.25 & 10 \\
0.75 & 15 \\
1.25 & 30 \\
\hline
\end{tabular}

willingness to invest in a complete renovation (not all owners can afford the costs), etc. [31].

Other flood parameters, e.g., flood duration or presence of contamination, might have a role in flood consequences, but still, in other case studies the correlation among these parameters was found low. Moreover, multivariable models can only be effectively developed and applied if sufficient and detailed data are available [7]. The main explicative variables that determine flood losses are usually water depth and building area.

Flow velocity, which could have been significant for a flash flood event, still does not appear to be correlated with flood damages $[7,32]$. This is probably due to the uncertainties of both the hydraulic model and the loss data, which are particularly significant in urban areas where building and linear infrastructure affect the flow propagation and are difficult to describe. More quantitative measurements to improve the validation of hydraulic simulation could be helpful in having a better representation of the flood propagation in those areas with limited crowd-sourced information.

As in other Italian cases $[7,31]$, the number of official claims is lower than the actual number of affected properties. Only approximately one-seventh of the exposed buildings based on the inundation model have associated claims. This means that some claims were not justified by invoices (i.e., black market) or owners preferred not the ask for a compensation of the flood losses (e.g., private insurance).

The aggregation of flood losses and water depths to census polygons instead of single building could be a way to smooth local differences and provide a mesoscale vulnerability function [31]. However, this would require a larger amount of data to obtain a significant number of empirical points.

The reconstruction with the same method of the inundation of the other catchments affected (Ardenza and other minor streams) could be used to (i) validate the model with an independent dataset, (ii) increase the sample of observations which might improve the quality of the vulnerability curve at single building and also (iii) offer the chance to test the aggregation at the census polygon scale.

\section{SN Applied Sciences}

\section{Conclusions}

The study focused on the development of an empirical vulnerability curve for residential buildings based on the reconstruction of a flash flood event and observed damage losses. The study area is the catchment of Rio Maggiore, Livorno, located in the coastal area of Tuscany (Italy).

Observed losses (about 300 records) were provided by the Regional Agency for Civil Protection. The flash flood event was reconstructed based on a distributed hydrologic model and a full 2D hydraulic model to obtain a flood depth map. Monetary exposure of residential buildings was estimated based on the building footprint and the market values.

A relative vulnerability curve was created by associating simulated water depths and relative losses. The curves showed a low correlation $\left(R^{2} \approx 0.2\right.$ and RMSE $\approx 20 \%$ ) between losses and flood parameters as observed in other case studies in the literature $[7,30]$ but the best regression was obtained with a second-order polynomial function [15].

A monetary vulnerability curve was created by associating simulated water depths and absolute losses per unit surface. The curve showed a better correlation $\left(R^{2} \approx 0.4\right.$ and $\mathrm{RMSE} \approx 450 € / \mathrm{m}^{2}$ ) with good regressions obtained by linear and second-order polynomial functions. A simple empirical curve obtained by a binning procedure was also generated with comparable performances. The curves provide the first attempt to derive empirical vulnerability functions for flash flooding in the Italian context and could be adopted for similar urban (i.e., multistory buildings, some with basement) and morphological contexts (semi-dense urban area, mild slopes).

Although the event had the characteristics of a flash flood, no significant correlation was found between losses (both relative and absolute) and flow velocity or magnitude. Still the physical damage mechanisms depending on several inundation parameters need to be clarified by further research, and the results of this work should be compared with other datasets when becoming available.

An extension of the work to the other catchment affected by the flash flood event could help in increasing the significance of the sample and obtaining different vulnerability curves. Locally identified empirical models in fact have been proven to be more effective than transferred models in both relative and absolute damage estimation. Moreover, empirical univariable models still represent a good compromise in the absence of extensive and accurate loss data and could provide a viable support at regional/local level for risk assessment and cost-benefit analysis of mitigation measures [33]. 
Acknowledgements Authors gratefully acknowledge the Italian Ministry of Education, University and Research who supported the first author within the framework of PRIN2015 Program, Project MICHe ("Mitigating the Impacts of natural hazards on Cultural Heritage sites, structures and artefacts").

\section{Compliance with ethical standards}

Conflict of interest On behalf of all authors, the corresponding author states that there is no conflict of interest.

\section{References}

1. IPCC (2014) Summary for Policymakers. Clim Chang. https://doi. org/10.1017/CBO9781107415324

2. Barredo Jl (2009) Normalised flood losses in Europe: 1970-2006. Nat Hazards Earth Syst Sci 9:97-104. https://doi.org/10.5194/ nhess-9-97-2009

3. Meyer V, Messner F (2005) National flood damage evaluation methods : a review of applied methods in England, the Netherlands, the Czech republic and Germany. 49

4. Arrighi $C$, Brugioni M, Castelli F, Franceschini S, Mazzanti B (2018) Flood risk assessment in art cities: the exemplary case of Florence (Italy). J Flood Risk Manag. https://doi.org/10.1111/ jfr3.12226

5. Dottori F, Figueiredo R, Martina M, Molinari D, Scorzini AR (2016) INSYDE: a synthetic, probabilistic flood damage model based on explicit cost analysis. Nat Hazards Earth Syst Sci Discuss. https:// doi.org/10.5194/nhess-2016-163

6. Luino F, Turconi L, Petrea C, Nigrelli G (2012) Uncorrected landuse planning highlighted by flooding: the Alba case study (Piedmont, Italy). Nat Hazards Earth Syst Sci 12:2329-2346. https:// doi.org/10.5194/nhess-12-2329-2012

7. Carisi F, Schröter K, Domeneghetti A, Kreibich $\mathrm{H}$, Castellarin A (2018) Development and assessment of uni- and multivariable flood loss models for Emilia-Romagna (Italy). Nat Hazards Earth Syst Sci 18:2057-2079. https://doi.org/10.5194/nhess -18-2057-2018

8. Amadio M, Rita Scorzini A, Carisi F, Essenfelder HA, Domeneghetti A, Mysiak J, Castellarin A (2019) Testing empirical and synthetic flood damage models: the case of Italy. Nat Hazards Earth Syst Sci 19:661-678. https://doi.org/10.5194/nhess-19-661-2019

9. Wagenaar D, De Jong J, Bouwer LM (2017) Multi-variable flood damage modelling with limited data using supervised learning approaches. Nat Hazards Earth Syst Sci 17:1683-1696. https:// doi.org/10.5194/nhess-17-1683-2017

10. Sturm M, Gems B, Keller F, Mazzorana B, Fuchs S, PapathomaKöhle M, Aufleger M (2018) Experimental analyses of impact forces on buildings exposed to fluvial hazards. J Hydrol 565:113. https://doi.org/10.1016/j.jhydrol.2018.07.070

11. Postacchini M, Zitti G, Giordano E, Clementi F, Darvini G, Lenci $S$ (2019) Flood impact on masonry buildings: the effect of flow characteristics and incidence angle. J Fluids Struct 88:48-70. https://doi.org/10.1016/j.jfluidstructs.2019.04.004

12. Habermann N, Hedel R (2018) Damage functions for transport infrastructure. Int J Disaster Resil Built Environ 9:420-434. https ://doi.org/10.1108/IJDRBE-09-2017-0052

13. Brémond $P$, Grelot $F$ (2013) Review Article: economic evaluation of flood damage to agriculture-review and analysis of existing methods. Nat Hazards Earth Syst Sci 13:2493-2512. https://doi. org/10.5194/nhess-13-2493-2013

14. Gerl T, Kreibich H, Franco G, Marechal D, Schröter K (2016) A review of flood loss models as basis for harmonization and benchmarking. PLoS ONE 11:1-22. https://doi.org/10.1371/ journal.pone.0159791

15. Fuchs S, Heiss K, Hübl J (2007) Towards an empirical vulnerability function for use in debris flow risk assessment. Nat Hazards Earth Syst Sci 7:495-506. https://doi.org/10.5194/nhess -7-495-2007

16. Laudan J, Rözer V, Sieg T, Vogel K, Thieken AH (2017) Damage assessment in Braunsbach 2016: data collection and analysis for an improved understanding of damaging processes during flash floods. Nat Hazards Earth Syst Sci 17:2163-2179. https:// doi.org/10.5194/nhess-17-2163-2017

17. Bermúdez M, Zischg AP (2018) Sensitivity of flood loss estimates to building representation and flow depth attribution methods in micro-scale flood modelling. Nat Hazards 92:1633-1648. https://doi.org/10.1007/s11069-018-3270-7

18. Arrighi C, Campo L (2019) Effects of digital terrain model uncertainties on high-resolution urban flood damage assessment. J Flood Risk Manag 12:1-12. https://doi.org/10.1111/jfr3.12530

19. Ballio F, Molinari D, Minucci G, Mazuran M, Arias Munoz C, Menoni S, Atun F, Ardagna D, Berni N, Pandolfo C (2018) The RISPOSTA procedure for the collection, storage and analysis of high quality, consistent and reliable damage data in the aftermath of floods. J Flood Risk Manag 11:S604-S615. https://doi. org/10.1111/jfr3.12216

20. Cammerer H, Thieken AH, Lammel J (2013) Adaptability and transferability of flood loss functions in residential areas. Nat Hazards Earth Syst Sci. https://doi.org/10.5194/nhess -13-3063-2013

21. Arrighi C, Castelli F (2020) the 2017 Flash flood of livorno (Italy): lessons learnt from an exceptional hydrologic event. In: Fernandes F, Malheiro A, Chaminé $\mathrm{H}$ (eds) Advances in natural hazards and hydrological risks: meeting the challenge. Advances in science, technology and innovation book series (ASTI), Springer, pp 117-120

22. Yang J, Castelli F, Chen Y (2014) Multiobjective sensitivity analysis and optimization of distributed hydrologic model MOBIDIC. Hydrol Earth Syst Sci 18:4101-4112. https://doi.org/10.5194/ hess-18-4101-2014

23. Castelli F, Menduni G, Mazzanti B (2009) A distributed package for sustainable water management: a case study in the Arno basin. IAHS-AISH Publ 327:52-61

24. Campo L, Caparrini F, Castelli F (2006) Use of multi-platform, multi-temporal remote-sensing data for calibration of a distributed hydrological model: an application in the Arno basin, Italy. Hydrol Process 20:2693-2712. https://doi.org/10.1002/hyp.6061

25. Brunner GW (CEIWR-H (2016) HEC-RAS River Analysis System, 2D Modeling User's Manual Version 5.0

26. Chow VT (1959) Open channel hydraulics. Mc Graw Hill Book Company INC, New York

27. Agenzia delle Entrate $\mathrm{OMI}(\mathrm{xxxx})$ Osservatorio Mercato Immobiliare. https://wwwt.agenziaentrate.gov.it/geopoi_omi/index .php. Accessed 27 Nov 2019

28. Arrighi C, Oumeraci $\mathrm{H}$, Castelli $\mathrm{F}$ (2017) Hydrodynamics of pedestrians' instability in floodwaters. Hydrol Earth Syst Sci. https:// doi.org/10.5194/hess-21-515-2017

29. Arrighi $C$, Alcèrreca-Huerta JC, Oumeraci H, Castelli $F$ (2015) Drag and lift contribution to the incipient motion of partly submerged flooded vehicles. J Fluids Struct. https://doi. org/10.1016/j.jfluidstructs.2015.06.010

30. Merz B, Kreibich H, Thieken A, Schmidtke R (2004) Estimation uncertainty of direct monetary flood damage to buildings. Nat Hazards Earth Syst Sci 4:153-163. https://doi.org/10.5194/nhess -4-153-2004

31. Molinari D, Scorzini AR, Arrighi C, Carisi F, Castelli F, Domeneghetti A, Gallazzi A, Galliani M, Grelot F, Kellermann P, Kreibich HGM, Moimann M, Natho S, Richert C, Schroeter K, Thieken A, Zischg 
AP, Ballio F (2007) Are flood damage models converging to reality? Lessons learnt from a blind test. NHESS Disc 1:10. https:// doi.org/10.5194/nhess-2020-40

32. Kreibich $H$, Piroth $K$, Seifert I, Maiwald H, Kunert U, Schwarz J, Merz B, Thieken AH (2009) Is flow velocity a significant parameter in flood damage modelling? Nat Hazards Earth Syst Sci 9:1679-1692. https://doi.org/10.5194/nhess-9-1679-2009

33. Arrighi $C$, Rossi $L$, Trasforini $E$, Rudari R, Ferraris $L$, Brugioni $M$, Franceschini S, Castelli F (2018) Quantification of flood risk mitigation benefits: a building-scale damage assessment through the RASOR platform. J Environ Manage 207:92-104. https://doi.org/10.1016/j.jenvman.2017.11.017

Publisher's Note Springer Nature remains neutral with regard to jurisdictional claims in published maps and institutional affiliations. 